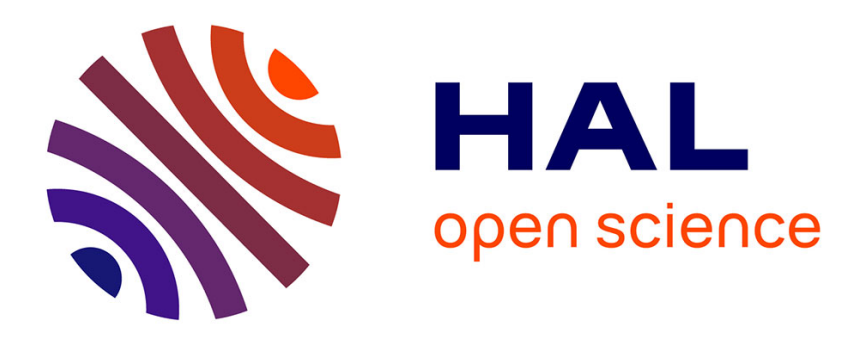

\title{
Data reproducibility in fluorescence image analysis.
} Catherine Souchier, Christine Brisson, Bernadette Batteux, Michel Robert-Nicoud, Paul-André Bryon

\section{To cite this version:}

Catherine Souchier, Christine Brisson, Bernadette Batteux, Michel Robert-Nicoud, Paul-André Bryon. Data reproducibility in fluorescence image analysis.. Methods in Cell Science, 2003, 25 (3-4), pp.195200. inserm-00333348

\section{HAL Id: inserm-00333348 https://www.hal.inserm.fr/inserm-00333348}

Submitted on 23 Oct 2008

HAL is a multi-disciplinary open access archive for the deposit and dissemination of scientific research documents, whether they are published or not. The documents may come from teaching and research institutions in France or abroad, or from public or private research centers.
L'archive ouverte pluridisciplinaire HAL, est destinée au dépôt et à la diffusion de documents scientifiques de niveau recherche, publiés ou non, émanant des établissements d'enseignement et de recherche français ou étrangers, des laboratoires publics ou privés. 
Area descriptor: Cell biology

\section{Data reproducibility in fluorescence image analysis}

Catherine Souchier ${ }^{1}$, Christine Brisson ${ }^{2}$, Bernadette Batteux ${ }^{1}$, Michel Robert-Nicoud $^{1} \&$ Paul-André Bryon ${ }^{3}$

${ }^{1}$ INSERM U309 - DyOGen, Institut Albert Bonniot, La Tronche, France

${ }^{2}$ INSERM U433, Laennec faculty, Lyon, France

${ }^{3}$ Analytical Cytology and Quantimetry Center, Rockefeller faculty, Lyon, France

\section{Address for correspondence:}

Catherine Souchier,

INSERM U309, DyOGen

Institut Albert Bonniot

Domaine de la Merci

38706 La Tronche, France

Tel: (+33) 476549466

Fax: (+33) 476549595

E-mail : Catherine.Souchier@ujf-grenoble.fr 


\section{Abstract}

Fluorescence image analysis provides quantitative data on fluorescence in situ hybridization signals (FISH), immunofluorescence labelings, Green Fluorescent Protein (GFP) expression and microarrays. It is a valuable tool for decision making in the fields of biology and medicine. The aim of this study was to evaluate the reproducibility of fluorescence intensity measurements and standardization when acquisitions are performed under various but well defined conditions.

Fluorescent intensity of standard beads (Inspeck series, Molecular Probes) was repeatedly measured using an image analyzer and automated procedures. Images were acquired using several integration times and neutral filter sets. A standardization procedure was used for expressing the data in a same unit: data were multiplied by the light attenuation factor and were divided by the CCD integration times. Results show that 1) standardization is possible 2) accurate and reliable fluorescence measurements can be obtained and 3) specimens showing large differences in fluorescence intensity can be objectively compared. Moreover fluorescent test slides including fluorochrome solutions and altuglas slides were tested for shading correction and as overall test systems.

Key words: Fluorescence microscopy, quantification, standards, cytometry, image analysis. 


\section{Introduction}

A great panel of fluorescence microscopy techniques is now available for in situ analyses on fixed and living cells. The availability of new fluorescent labeling reagents, such as Alexa probes [10], makes it possible to choose an optimal fluorophore within a defined wavelength range. The expression of fluorescent chimeric proteins (Green Fluorescent Protein (GFP) and variants) [4,7] has become a widely used methodology to study the behavior of proteins in living cells. In parallel, high resolution, multi-mode and automated fluorescence microscopes have been developed with improved and new performances for analyzing protein dynamics and interactions. Fluorescence image analysis allows us to measure concentrations of fluorescent probes in cells with microscope spatial resolution. It can be used for quantification of in situ hybridization signals, immunofluorescence labeling, fluorescence staining, Green Fluorescent Protein (GFP) expression and for microarray reading [3]. With quantitative and objective data, it is possible to better detect changes, i.e. in fluorescence intensity or in the extent of labeling, and to classify specimen and interpret the results in relationships with experimental, functional, biochemical or clinical data. Quantitative digital imaging has many potential applications, however several controls are required before accurate and reliable measurements can be made [5]. In fluorescence quantification, one problem is to avoid that data depend upon the quality of the labeling and on the conditions of the measurement. Standardization is specially required for 
comparison of intensity data obtained on different specimens and on different days. First, fluorescent solutions and stained plastic or glass slides were used for shading correction and overall system control. The interest of samples with reproducible fluorescence yield was previously discussed by Model et al [8]. Secondly, solutions and microspheres (Inspeck series, Molecular Probes ${ }^{1}$ ) labeled with increasing amounts of fluorochromes were measured. The Inspeck beads have already been used as standards in image cytometry by other groups $[1,2,6,13]$. In this study, we analyzed the reproducibility of fluorescence intensity measurements, and the possible standardization when acquisitions are performed using controlled but different conditions. Our aim was to obtain instrument- and acquisition mode- independent fluorescence data. Our results show that reproducibility can be obtained even when image capture is performed with various neutral filter sets or integration times. The main advantage of the standardization is to make possible comparison of data obtained not only on different days but also on specimens showing a large fluorescent intensity range.

\section{Materials and Methods}

\section{Uniform fluorescent specimens}

Several colored plastics or glasses kindly provided by a mirror and glass seller $\left(\right.$ Targe $^{2}$ ) and a manufacturer (fluorescent acrylic sheets ALTUMAX, PMMA 12731000, 12732000, 12733000, Atofina ${ }^{3}$ ) were 
tested. Fluorescent solutions with various concentrations of Alexa 488 streptavidin (S-11223, Molecular Probes ${ }^{1}$ ) were also used.

\section{Calibration beads}

Inspeck fluorescent latex microspheres series (Molecular Probes ${ }^{1}$ ) labeled with increasing amounts of dyes $(0 \% ; 0.3 \%, 1 \%, 10 \%, 30 \%$ and $100 \%$ ) were used (Table I).

[Table 1 approx. here]

\section{Image analysis system}

The study was performed on a Quantimet 600 image analysis system (Leica $\left.{ }^{4}\right)$, equipped with a tri-CCD (Charge-Coupled Device) color camera (DXC $930 \mathrm{P}$, Sony ${ }^{5}$ ). The slides were observed under the DMRBE ("Das Mikroskop" Research Biology Electronic) upright microscope (Leica ${ }^{6}$ ) using a X63 plan-fluotar objective (NA=1.3) and three filter sets (Table 2). The microscope stage, focus, fluorescent shutter and the CCD integrating camera were under software control. Ready to use interactive software allows the users to built up their own applications.

[Table 2 approx. here]

Fluorescence images were acquired and then corrected for uneven illumination according to the formula[12]:

$$
I F_{x, y, \text { corrected }}=\frac{I F_{x, y, \text { measured }}-I F_{x, y, \text { black }}}{I F_{x, y, \text { white }}-I F_{x, y, \text { black }}} * k \text {, }
$$




$$
I F_{x, y}: \text { fluorescence intensity of the pixel }(x, y)
$$

When images were acquired under two or three acquisition conditions, involving different integration times or neutral filter sets, mean fluorescence intensity $(I F)$ data were expressed on a common scale using the following equation:

$$
I F_{\text {standardized }}=I F_{\text {measured }} \frac{\text { light attenuation }}{\text { integration time }}
$$

For instance, the light attenuation was equal to 2 using a ND2 neutral filter, the integration time to 4 when the signal was being integrated during $4 \mathrm{~s}$.

\section{Results}

\section{Uneven illumination correction}

One of the aims of this work was to identify the most convenient specimen for shading correction. Acquisition from an uniformly fluorescent image, the white image in the equation, is needed. Most of the plastic or colored glass specimens we have tested were uniformly fluorescent, however with spectral and intensity differences. A good product was the fluo-green altuglas slide (Atofina ${ }^{3}$ ), as already reported at ISAC meeting [9]. It can be used in the blue, green and red emission ranges. Gray levels were adjusted using a neutral filter set and an integration time. We used these slides as microscope slides with a coverslip for surface protection against dirt and scratches, and also because images were acquired with an 
objective lens corrected for coverslip. Another way was to use solutions of fluorochromes at various concentrations, and thus at various fluorescent intensity levels. We found convenient to prepare them using a commercial product proposed for in situ hybridization technique ( $25 \mu$ l easy seal, HBOS-SSEZIE, Hybaid $\operatorname{Ltd}^{7}$ ). However, the solution was covered by a glass microscope coverslip. It was possible to keep the preparations for a few days, in the dark, at $4^{\circ} \mathrm{C}$.

\section{Fluorescence standardization}

One problem in fluorescence quantification arises when specimen with large differences in fluorescence intensity have to be measured. In these cases, it can be useful to acquire images using different but wellcontrolled conditions. It is therefore necessary to standardize the data for expressing them in the same unit.

First, images were acquired using different neutral filter sets and data were then standardized assuming linear relationships between the fluorescence emission and the intensity of the illumination. The measurements were carried out using a software enabling us for sequential acquisitions of two images with two different neutral filter sets. Measured ratios were correlated to the known filter attenuation values (Figure 1-A) and standardized fluorescence intensities were obtained whatever the neutral filter set used during image acquisition (Figure 1-B). However, the value for the $1 / 16$ attenuation neutral filter had to be considered as only $1 / 14$ attenuation, as also confirmed using a Kontron uvikon 860 
Spectrofluorimeter. Second, images were acquired with different integration times, and standardized fluorescence intensities were also obtained whatever the integration acquisition time (Figure 2).

[Figure 1 and 2 approx. here]

\section{Data calibration}

The main work addressed the standardization problem. Our aim was to obtain instrument-, time- and specimen- independent fluorescence intensity measurements. Slides with blue, green, and red inspeck microspheres or solutions of Alexa streptavidin, all with increasing amounts of fluorochromes were prepared and measured several times. The A specimen was measured two times on two different days. The analysis was performed after image captures using several neutral filter sets and integration times and the mean fluorescence intensities were standardized and expressed in the same unit. The results were summarized in Tables 3 to 5 for the microspheres and in Table 6 for the solutions of Alexa 488. The median value is shown in the last column. First, close data were obtained independent on the day or the conditions of acquisition. Moreover, as expected, the intensity increased according to the amount of dyes on the microspheres and to the Alexa concentrations of the solutions.

[Table 3 to 5 approx. here]

[Table 6 approx. here]

\section{Discussion}


Data were obtained after preparation and analysis of Inspeck beads at different times during a period of three months. First, it should be noted that the results were obtained under rigorous control of offset and brightness. These parameters were fixed and set in the software. Second, we were careful not to reach the saturation level, and the measurements were kept in the range $20-220$ within the 255 gray scale.

On the whole, reproducible standardized data were obtained, even when the neutral filter sets or the integration times were modified. However, results were better for the green and red series, than for the blue one. The values obtained for the $100 \%$ blue component were significantly lower after two months (D sample), and this observation was confirmed by further series of measurements. The loss of fluorescence of the $100 \%$ blue beads was not related to experimental events. On the contrary, two data were due to an experimental mistake, the $30 \%$ component of the blue A sample, measured a second time (B) was undoubtedly a $10 \%$ component.

The fact that fluorescence specimens may change during time is probably the main drawback for using them as standard. However, according to our experience, discrepancies between measurements and expected fluorescence values reflect most often a problem in the overall configuration of the image analyzer. In this sense, such test slides are undoubtedly useful. Moreover, when unexpected values of fluorescence intensity are obtained, a new standard may be prepared and stock solutions of fluorochromes may be stored in the dark during several weeks [8]. In 
addition, Altuglas slides may be efficiently used for background correction and overall system control.

Significant correlations were obtained between our measurements and the fluorescent intensity levels specified for the Inspeck beads. However, the relation was not strictly proportional. For further measurements, it would be possible to correct the data, taking into account the discrepancies between the observed (measured using the image analysis system) and the theoretical values (Molecular Probes). Our results demonstrate that the image analysis system provides reproducible and linear data. Standardization using neutral filters as shown in this study was possible. It was also confirmed by expected results concerning fluorescence quantification of nuclear DNA [11]. Therefore, we have to consider the possibility that "the true values" of the fluorescence beads were, after slide preparation, not exactly the same than in solution and under the analysis conditions used by Molecular Probes. Moreover, it is important to state that when cells and tissue sections are analyzed, preparative methods must also be controlled, and biological variations must be taken into account in the sampling design and in the interpretation of the fluorescent data.

After standardization, nearly identical data were obtained when the same specimens were analyzed after changing neutral filter sets or integration times. This is the main conclusion of this work. Indeed, it opens the possibility for measuring and comparing specimens under optimized conditions, even when only 8-bit image may be acquired. However, neutral filter specifications should be previously checked using sequential 
acquisitions. The study was performed using the Quantimet 600 image analyzer. However, similar performances could be expected with other systems provided that they allow the users to software control the microscope and the camera and to built up their own applications.

\section{Notes on suppliers}
A. Molecular Probes, Eugene, Oregon, USA
B. Targe, Lyon, France
C. Atofina, department altuglas, Paris, France
D. Leica-microsystems, Cambridge, UK
E. Sony, Japan
F. Leica-microsystems, Wetzlar, Germany
G. Hybaid Ltd, Teddington Middlesex, UK

\section{References}

1. Bezakova G, Helm JP, Francolini M, Lomo T. Effects of purified recombinant neural and muscle agrin on skeletal muscle fibers in vivo. J Cell Biol.2001; 153: 1441-52.

2. Bour-Dill C, Gramain MP, Merlin JL, Marchal S, Guillemin F. Determination of intracellular organelles implicated in daunorubicin cytoplasmic sequestration in multidrug-resistant MCF-7 cells using fluorescence microscopy image analysis. Cytometry.2000; 39: 1625.

3. Forster T, Roy D, Ghazal P. Experiments using microarray technology: limitations and standard operating procedures. $\mathbf{J}$ Endocrinol.2003; 178: 195-204.

4. Holmes KL, Lantz LM. Protein labeling with fluorescent probes. Methods Cell Biol.2001; 63: 185-204. 
5. Jonker A, Geerts WJ, Chieco P, Moorman AF, Lamers WH, Van Noorden CJ. Basic strategies for valid cytometry using image analysis. Histochem J. 1997; 29: 347-64.

6. Jovov B, Tousson A, Ji HL, Keeton D, Shlyonsky V, Ripoll PJ, Fuller CM, Benos DJ. Regulation of epithelial $\mathrm{Na}(+)$ channels by actin in planar lipid bilayers and in the Xenopus oocyte expression system. J Biol Chem. 1999; 274: 37845-54.

7. Lippincott-Schwartz J, Patterson GH. Development and use of fluorescent protein markers in living cells. Science.2003; 300: 87-91.

8. Model MA, Burkhardt JK. A standard for calibration and shading correction of a fluorescence microscope. Cytometry. 2001; 44: 30916.

9. Netten H, Ellenberger SL, Young IT. 1996. Illumination calibration for fluorescence microscopy. In International society for analytical cytology. Vol. Supplement 8, Abstract 57. Cytometry, Rimini, Italy. 109.

10. Panchuk-Voloshina N, Haugland RP, Bishop-Stewart J, Bhalgat MK, Millard PJ, Mao F, Leung WY. Alexa dyes, a series of new fluorescent dyes that yield exceptionally bright, photostable conjugates. J Histochem Cytochem. 1999; 47: 1179-88.

11. Souchier C, Ffrench M, Benchaib M, Catallo R, Bryon PA. Methods for cell proliferation analysis by fluorescent image cytometry. Cytometry. 1995; 20: 203-09.

12. Vigo J, Salmon JM, Lahmy S, Viallet P. Fluorescent image cytometry: from qualitative to quantitative measurements. Anal Cell Pathol.1991; 3: 145-65.

13. Vischer NO, Huls PG, Ghauharali RI, Brakenhoff GJ, Nanninga N, Woldringh CL. Image cytometric method for quantifying the relative amount of DNA in bacterial nucleoids using Escherichia coli. J Microsc. 1999; 196: 61-68.

\section{Acknowledgments}

This work was supported by ARC "Association for Research Cancer" grant. 
Table 1. Inspeck calibration bead features

\begin{tabular}{lllr}
\hline Reference & Molecular Probes & Diameter & Excitation/Emission \\
I-7221 & InSpeck Blue & $2.5 \mu \mathrm{m}$ & $350 \mathrm{~nm} / 440 \mathrm{~nm}$ \\
I-7219 & InSpeck Green & $2.5 \mu \mathrm{m}$ & $505 \mathrm{~nm} / 515 \mathrm{~nm}$ \\
I-7223 & InSpeck Orange & $2.5 \mu \mathrm{m}$ & $540 \mathrm{~nm} / 560 \mathrm{~nm}$ \\
\hline
\end{tabular}


Table 2. Fluorescence filter sets

\begin{tabular}{llll}
\hline Emission range & Excitation filter & Dichroic Mirror & Emission filter \\
\hline Blue & BP $360 / 20 \mathrm{~nm}$ & DM $400 \mathrm{~nm}$ & LP $425 \mathrm{~nm}$ \\
Green & BP $470 / 20 \mathrm{~nm}$ & DM $510 \mathrm{~nm}$ & LP 515-560 nm \\
Red & BP 515-560 nm & DM 580 nm & LP 590 nm \\
\hline
\end{tabular}

BP: Band Pass, DM: Dichroic Mirror, LP: Long Pass 
Table 3. Measurement of green fluorescent microspheres

\begin{tabular}{rcccccc}
\hline & A, time 1 & A, time2 & B & C & D & Median (\%) \\
\hline $0.3 \%$ & $6.3^{\circ} \pm 0.04$ & $3.5 \pm 0.04$ & $3.7 \pm 0.03$ & $3.3 \pm 0.05$ & $3.3 \pm 0.06$ & $3.5(0.2 \%)$ \\
$1 \%$ & $19 \pm 0.1$ & $17 \pm 0.4$ & $18 \pm 0.2$ & $15 \pm 0.2$ & $15 \pm 0.2$ & $17(0.7 \%)$ \\
$3 \%$ & $93 \pm 0.9$ & $112 \pm 1.0$ & $111 \pm 1.4$ & $102 \pm 1.5$ & $96 \pm 1.1$ & $102(4.5 \%)$ \\
$10 \%$ & $197 \pm 1.1$ & $207 \pm 2$ & $235 \pm 3$ & $241 \pm 3$ & $192 \pm 6$ & $207(9.0 \%)$ \\
$30 \%$ & $494 \pm 3$ & $640 \pm 6$ & $629 \pm 8$ & $618 \pm 8$ & $492 \pm 10$ & $618(27 \%)$ \\
$100 \%$ & $2368 \pm 13$ & $2107 \pm 24$ & $1927 \pm 47$ & $2425 \pm 23$ & $2288 \pm 22$ & $2288(100 \%)$ \\
\hline \multicolumn{5}{c}{ mean \pm sem, arbitrary units } & &
\end{tabular}


Table 4. Measurement of red fluorescent microspheres

\begin{tabular}{rcccccc}
\hline & A, time 1 & A, time2 & B & C & D & Median (\%) \\
\hline $0.3 \%$ & $21^{\circ} \pm 0.3$ & $20 \pm 0.3$ & $21 \pm 0.2$ & $22 \pm 0.3$ & $13 \pm 0.2$ & $20.0(0.4 \%)$ \\
$1 \%$ & $39 \pm 0.4$ & $39 \pm 0.6$ & $27 \pm 0.6$ & $40 \pm 1.5$ & $24 \pm 0.8$ & $39(0.8 \%)$ \\
$3 \%$ & $116 \pm 1$ & $121 \pm 1$ & $135 \pm 3$ & $139 \pm 3$ & $107 \pm 3$ & $116(2.3 \%)$ \\
$10 \%$ & $370 \pm 5$ & $394 \pm 4$ & $421 \pm 6$ & $464 \pm 6$ & $414 \pm 11$ & $414(8.4 \%)$ \\
$30 \%$ & $944 \pm 13$ & $966 \pm 9$ & $969 \pm 17$ & - & $981 \pm 17$ & $967(19.5 \%)$ \\
$100 \%$ & $5059 \pm 40$ & $4429 \pm 68$ & $5186 \pm 49$ & $4465 \pm 58$ & $4936 \pm 85$ & $4936(100 \%$ \\
\hline \multicolumn{7}{c}{${ }^{\circ}$ mean \pm sem, arbitrary units }
\end{tabular}


Table 5. Measurement of blue fluorescent microspheres

\begin{tabular}{rcccccc}
\hline & A, time 1 & A, time2 & B & C & D & Median (\%) \\
\hline $0.3 \%$ & $4.6^{\circ} \pm 0.1$ & $3.8 \pm 0.1$ & $3.8 . \pm 0.2$ & $3.3 . \pm 0.1$ & $3.1 \pm 0.1$ & $3.8(0.3 \%)$ \\
$1 \%$ & $9.9 \pm 0.3$ & $9.4 \pm 0.2$ & $9.2 . \pm 0.4$ & $7.4 \pm 0.4$ & $4.9 \pm 0.2$ & $9.2(0.8 \%)$ \\
$3 \%$ & & $75 \pm 2$ & $88 \pm 1$ & $68 \pm 1.3$ & $70 \pm 2$ & $72(6.5 \%)$ \\
$10 \%$ & $121 \pm 4$ & $101 \pm 2$ & $156 \pm 2$ & $152 \pm 4$ & $91 \pm 2$ & $121(10.8 \%)$ \\
$30 \%$ & $116 \pm 2$ & $106 \pm 3$ & $290 \pm 4$ & $247 \pm 3$ & $228 \pm 4$ & $228(20.5 \%)$ \\
$100 \%$ & $1167 \pm 43$ & $1113 \pm 46$ & $1236 \pm 57$ & $945 \pm 46$ & $442 \pm 10$ & $1113(100 \%)$ \\
\hline \multicolumn{7}{c}{ mean \pm sem, arbitrary units }
\end{tabular}




\begin{tabular}{|c|c|c|c|c|}
\hline & A & B & $\mathrm{C}$ & Median \\
\hline $0.25 \mu \mathrm{g} / \mathrm{ml}$ & $0.7^{\circ} \pm 0.01$ & $0.8 \pm 0.01$ & $0.5 \pm 0.01$ & 0.7 \\
\hline $0.5 \mu \mathrm{g} / \mathrm{ml}$ & $3.3 \pm 0.02$ & $1.1 \pm 0.01$ & $1.1 \pm 0.01$ & 1.1 \\
\hline $1 \mu \mathrm{g} / \mathrm{ml}$ & $2.0 \pm 0.05$ & $1.6 \pm 0.01$ & $2.0 \pm 0.02$ & 2.0 \\
\hline $2 \mu \mathrm{g} / \mathrm{ml}$ & $5.9 \pm 0.05$ & $2.5 \pm 0.01$ & $4.3 \pm 0.05$ & 4.3 \\
\hline $3.5 \mu \mathrm{g} / \mathrm{ml}$ & $12.1 \pm 0.07$ & $7.3 \pm 0.02$ & $9.6 \pm 0.03$ & 9.6 \\
\hline $5 \mu \mathrm{g} / \mathrm{ml}$ & $27.4 \pm 0.08$ & & $23.7 \pm 0.43$ & 25.5 \\
\hline
\end{tabular}




\title{
Figure legends
}

Figure 1. Acquisition using neutral filters

\begin{abstract}
A. Correlation between fluorescence ratio and neutral filter ratio, after sequential measurement using two different neutral filters. B. Two specimens were measured using neutral filter sets with attenuation from 14 to 4 (specimen a) and from 11.2 to 2.8 (specimen b). Data were then standardized.
\end{abstract}

Figure 2. Acquisition using exposure times

Two specimens were measured using exposure times from $t=2$ to $24 \mathrm{~s}$ (specimen a) to $12 \mathrm{~s}$ (specimen b). Data were then standardized. 

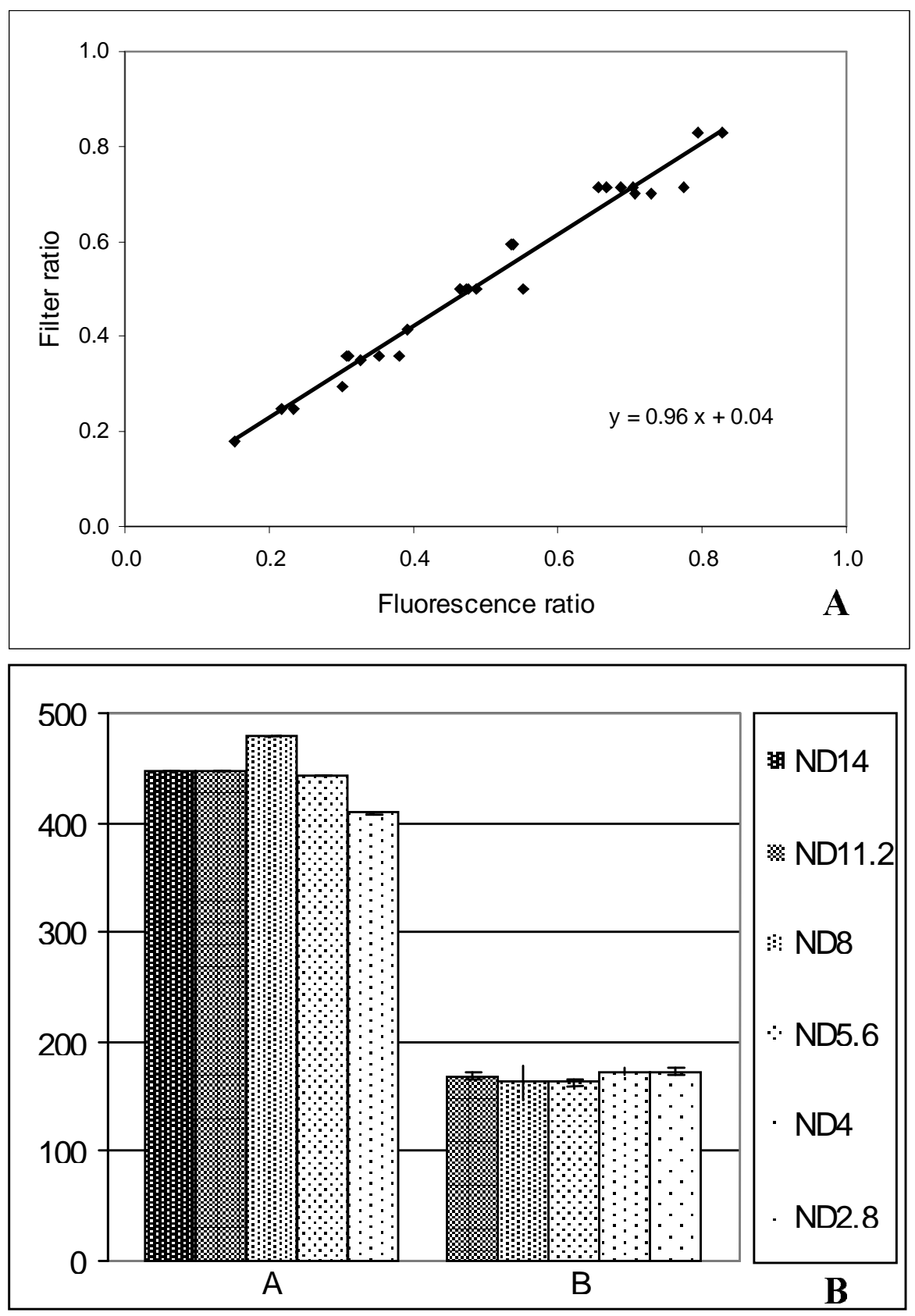


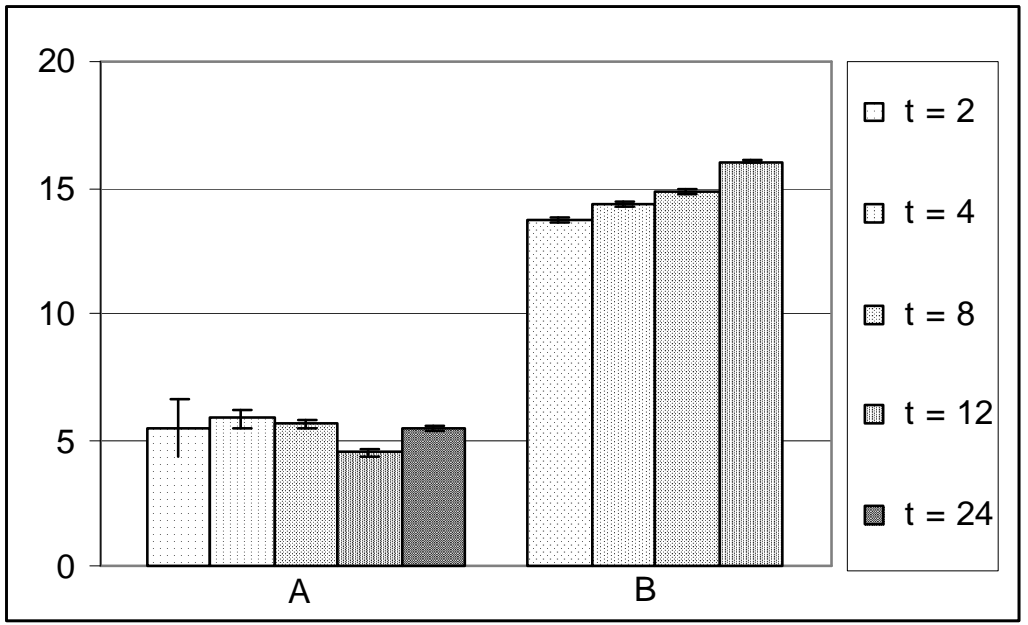

